\title{
UM MAPEAMENTO DE PESQUISAS BRASILEIRAS SOBRE O PIBID E A FORMAÇÃO INICIAL DE PROFESSORES DE MATEMÁTICA
}

\author{
A MAPPING OF BRAZILIAN RESEARCH ON PIBID AND THE INITIAL \\ TEACHER TRAINING OF MATHEMATICS
}

\author{
UN MAPA DE LA INVESTIGACIÓN BRASILEÑA SOBRE PIBID Y LA \\ FORMACIÓN INICIAL DE PROFESORES DE MATEMÁTICAS
}

\author{
Marcos Antonio de Sousa* (D.) \\ Deive Barbosa Alves** (D) 9 \\ Ulisses Queiroz Parreira***.(D)
}

\begin{abstract}
RESUMO
O presente artigo apresenta um mapeamento de pesquisas brasileiras que abordam o Pibid e a formação inicial de professores de matemática. Para tanto, realizamos um levantamento bibliográfico de pesquisas junto à Biblioteca Digital Brasileira de Teses e Dissertações (BDTD) e ao Catálogo de Teses e Dissertações da Capes. Dessa forma, buscamos responder a seguinte questão norteadora: "Que aspectos e dimensões vêm sendo destacados e privilegiados nas pesquisas de mestrado e doutorado que envolvem o Programa Institucional de Bolsas de Iniciação à Docência (Pibid) de matemática e a formação inicial de professores?" Como objetivo geral temos o de observar de que modo as pesquisas percebem o Pibid como um espaço de formação inicial de professores de matemática. Sendo assim, para construção do corpus de estudo foram selecionadas trinta e sete pesquisas, sendo dissertações e teses defendidas no período de 2012 a 2019. As pesquisas foram identificadas e analisadas a partir de seus objetivos, resultados, metodologia e análise de dados. Assim, a partir dos dados levantados, foi possível construir eixos temáticos que, em sua maioria, contemplam a formação inicial de futuros professores de matemática. Como resultado, as pesquisas apontaram o Pibid como mais um espaço para a formação inicial de professores e também de formação continuada e que o programa permite construir saberes docentes, possibilitando reflexões sobre as práticas formativas desenvolvidas, além de inserir o futuro professor nas práticas de ensinar e aprender.
\end{abstract}

Palavras-chave: Formação inicial de professores. Pibid. Educação Matemática.

\footnotetext{
* Mestrando do Programa de Pós-Graduação em Ensino de Ciências e Matemática (PPGecim) da Universidade Federal do Tocantins (UFT). Técnico Administrativo na Universidade Federal do Tocantins (UFT), Câmpus de Araguaína/TO, Brasil. Rua 15 Qd. 19 Lt. 02, Conjunto Residencial Patrocínio, Araguaína/TO, Brasil, CEP 77.826618. e-mail: marcos.sousa@uft.edu.br.

** Doutor em Educação e Ciências em Matemática pela Universidade Federal de Uberlândia (UFU). Professor do curso de Licenciatura em Matemática da Universidade Federal do Tocantins (UFT), Câmpus de Araguaína/TO. Professor do Programa de Pós-Graduação em Ensino de Ciências e Matemática (PPGecim) da Universidade Federal do Tocantins (UFT), Câmpus de Araguaína/TO, Brasil. Rua L, nº 272 Apto. 303, Setor Couto Magalhães, Araguaína/TO, Brasil, CEP 77.824-740. e-mail: deive@uft.edu.br.

*** Mestrando do Programa de Pós-Graduação em Ensino de Ciências e Matemática (PPGecim) da Universidade Federal do Tocantins (UFT). Professor de Matemática da Escola SESI de Araguaína/TO, Brasil. Rua da Prata, Qd. K6, Lt. 07, Setor Araguaína Sul, Araguaína/TO, Brasil, CEP 77.827-310. e-mail: uliqp @uft.edu.br.
} 


\begin{abstract}
This article presents a mapping of Brazilian research that address Pibid and the initial formation of mathematics teachers. Therefore, we conducted a bibliographic survey of research at the Brazilian Digital Library of Theses and Dissertations (BDTD) and the Capes Theses and Dissertations Catalog. Thus, we sought to answer the following guiding question: "What aspects and dimensions have been highlighted and privileged in master's and doctoral research involving the Institutional Program for Initiation Teaching Scholarships (Pibid) in Mathematics and initial teacher education?" As a general objective, we have to observe how research perceive Pibid as a space for the initial formation of mathematics teachers. Thus, for the construction of the study corpus, thirty-seven research were selected, with dissertations and theses being defended from 2012 to 2019. The research was identified and analyzed based on their objectives, results, methodology and data analysis. Thus, from the data collected, it was possible to build thematic axes that, for the most part, include the initial training of future mathematics teachers. As a result, the surveys pointed out Pibid as another space for initial teacher education and for continuing education, and that the program allows the construction of teacher knowledge, enabling reflections on the developed training practices, in addition to inserting the future teacher in teaching practices and learn.
\end{abstract}

Keywords: Initial teacher education. Pibid. Mathematical Education.

\title{
RESUMEN
}

Este artículo presenta un mapeo de las investigaciones brasileñas que abordan Pibid y la formación inicial de profesores de matemáticas. Por lo tanto, realizamos un levantamiento bibliográfico de las investigaciones de la Biblioteca Digital Brasileña de Tesis y Disertaciones (BDTD) y del Catálogo de Tesis y Disertaciones de Capes. Así, buscamos dar respuesta a la siguiente pregunta orientadora: "¿Qué aspectos y dimensiones se han destacado y privilegiado en la investigación de maestría y doctorado del Programa Institucional de Becas de Iniciación a la Docencia (Pibid) en Matemática y formación inicial docente?" Como objetivo general, tenemos que observar cómo las investigaciones perciben a Pibid como un espacio para la formación inicial de los profesores de matemáticas. Así, para la construcción del corpus de estudio se seleccionaron treinta y siete investigaciones, siendo las disertaciones y tesis defendidas de 2012 a 2019. Las investigaciones fueron identificadas y analizadas en base a sus objetivos, resultados, metodología y análisis de datos. Así, a partir de los datos recolectados, fue posible construir ejes temáticos que, en su mayor parte, incluyen la formación inicial de los futuros profesores de matemáticas. En consecuencia, las encuestas señalaron a Pibid como un espacio más para la formación inicial docente y también para la formación continua, y que el programa permite la construcción del conocimiento docente, posibilitando reflexiones sobre las prácticas formativas desarrolladas, además de insertar al futuro docente en la docencia. practica y aprende.

Palabras clave: Formación docente inicial. Pibid. Educación Matemática.

\section{INTRODUÇÃO}

A formação inicial docente necessita de ações que possibilitem uma prática docente mais abrangente? A partir desta problemática a Coordenação de Aperfeiçoamento de Pessoal de Nível Superior (CAPES), por meio da sua Diretoria de Formação de Professores da Educação Básica (DEB), passou a ofertar programas para a formação de professores que, dentre os principais temos: o Programa Institucional de Bolsa de Iniciação à Docência (Pibid), o Plano Nacional de Formação de Professores da Educação Básica (Parfor), o ProF Licenciatura - 
Programa de Fomento à Formação de Professores da Educação Básica, os Programas de Cooperação Internacional de Formação de Professores da Educação Básica e o Programa de Residência Pedagógica. Dentre eles, o presente estudo abrangerá o Pibid.

Para a Capes (2019), o Pibid tem por finalidade proporcionar aos discentes da primeira metade dos cursos de licenciatura uma inserção no cotidiano das escolas públicas de educação básica, contribuindo para o aperfeiçoamento da formação de docentes em nível superior. Em um estudo avaliativo realizado sobre o Pibid, Gatti et al. (2014) aponta que o programa além de ser formação inicial para os alunos das licenciaturas é, também, formação continuada para os professores das escolas públicas e professores das instituições de ensino superior participantes e, com isso o programa abre oportunidades de estudos, pesquisa e extensão.

Como percebemos, o programa envolve vários personagens, que vão desde alunos da escola básica até professores de instituições superiores de ensino. Entretanto, o público-alvo do programa são os alunos dos cursos de licenciatura ofertados na modalidade presencial ou no âmbito do Sistema Universidade Aberta do Brasil (UAB), por Instituições de Ensino Superior (IES) públicas e privadas sem fins lucrativos. O programa possui os seguintes objetivos de acordo com a Capes $(2019$, p. 1):

\footnotetext{
I - incentivar a formação de docentes em nível superior para a educação básica; II - contribuir para a valorização do magistério;

III - elevar a qualidade da formação inicial de professores nos cursos de licenciatura, promovendo a integração entre educação superior e educação básica;

IV - inserir os licenciandos no cotidiano de escolas da rede pública de educação, proporcionando-lhes oportunidades de criação e participação em experiências metodológicas, tecnológicas e práticas docentes de caráter inovador e interdisciplinar que busquem a superação de problemas identificados no processo de ensinoaprendizagem;

V - incentivar escolas públicas de educação básica, mobilizando seus professores como com formadores dos futuros docentes e tornando-as protagonistas nos processos de formação inicial para o magistério;

VI - contribuir para a articulação entre teoria e prática necessárias à formação dos docentes, elevando a qualidade das ações acadêmicas nos cursos de licenciatura.
}

Diante disso, a partir dos objetivos do programa, ressaltamos a proposta do Pibid em relação à sua dinâmica de ação: 


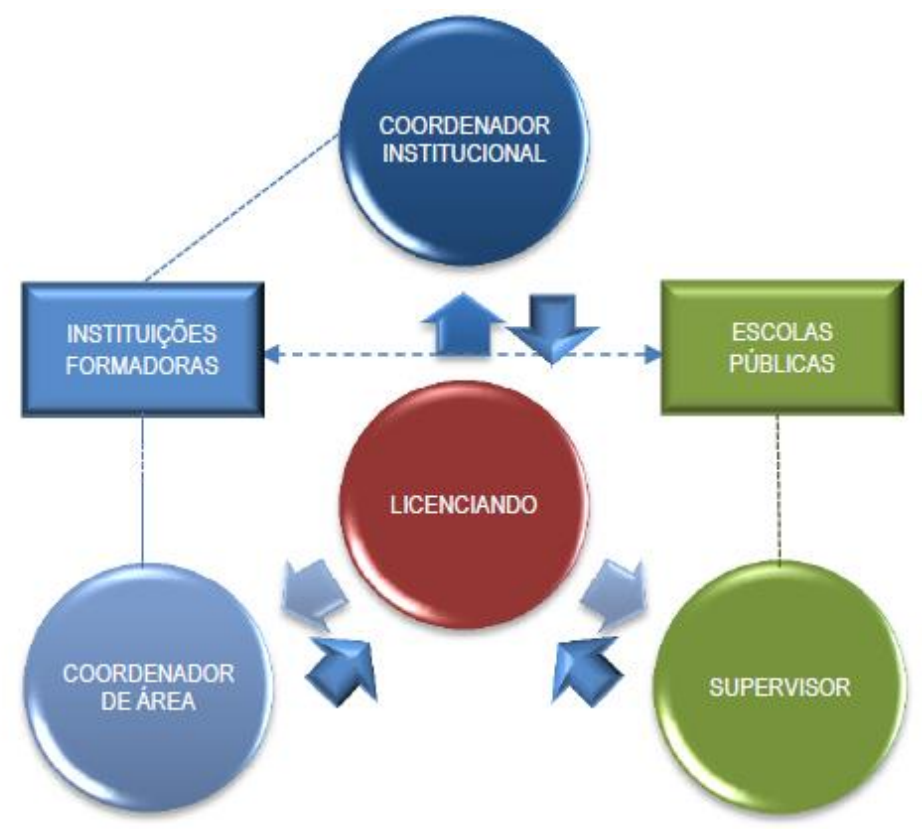

Figura 1 - Dinâmica do Pibid/CAPES

Fonte: Relatório de Gestão Capes/Diretoria de Educação Básica Presencial (DEB) 2009-2014

Observa-se o estudante de licenciatura ao centro do processo de formação docente recebendo apoio e realizando interações com diversos agentes da educação. Assim, todos têm uma participação efetiva no processo de aprendizagem. Por conseguinte, apresentamos a descrição dos agentes do programa de acordo com a CAPES (2009, p. 3, grifos nosso):

Coordenador institucional é um professor da instituição federal ou estadual responsável perante a CAPES por garantir e acompanhar o planejamento, a organização e a execução das atividades previstas no projeto de sua instituição, zelando por sua unidade e qualidade.

Coordenadores de área são os professores da instituição federal ou estadual responsáveis pelo planejamento, organização e execução das atividades previstas para a sua área, pelo acompanhamento dos alunos e pela articulação e diálogo com as escolas públicas onde os bolsistas exercem suas atividades, tendo em vista o compromisso do programa com a qualidade da educação.

Professor supervisor é o docente das escolas públicas estaduais e municipais participantes do projeto e é o responsável por supervisionar as atividades dos bolsistas de iniciação à docência, contribuindo para facilitar a articulação entre teoria e prática e para tornar a escola pública protagonista na formação dos futuros docentes.

Bolsistas de iniciação à docência são os estudantes dos cursos de licenciatura plena que integram o projeto institucional, com dedicação de uma carga horária mínima de 30h (trinta horas) mensais ao Pibid.

Diante do exposto, a partir da questão de estudo "Que aspectos e dimensões vêm sendo destacados e privilegiados nas pesquisas de mestrado e doutorado que envolvem o Pibid de matemática e a formação inicial de professores?", desencadeamos o objetivo geral que é 
compreender de que modo as pesquisas percebem o Pibid como um espaço de formação inicial de professores de matemática. O corpus de análise que sustenta o presente artigo é composto por trinta e sete dissertações e teses defendidas entre os anos de 2012 a 2019. Como justificativa de estudo destaca-se que este artigo é parte de uma pesquisa de mestrado em andamento, além de buscar discutir aspectos sobre o Pibid já analisados em pesquisas anteriores e ainda que levantamentos do tipo Revisões de Mapeamento de pesquisas vêm sendo bastante discutidas atualmente.

Em síntese, o texto trata de uma pesquisa qualitativa (BOGDAN; BIKLEN, 1994) a partir do mapeamento de pesquisas brasileiras, junto a periódicos como BDTD e CAPES, sobre o Pibid como espaço de formação inicial de professores de Matemática.

Adiante, discorremos sobre o percurso metodológico empregado no presente artigo. Posteriormente apresentamos o panorama sobre pesquisas brasileiras que envolvem o Pibid e a formação inicial de professores de matemática e, por fim, expomos as conisderações finais sobre a pesquisa.

\section{METODOLOGIA}

Inicialmente, cabe ressaltar que a leitura do corpus de análise foi realizada na íntegra com produções de fichas para cada pesquisa analisada e, posteriormente, foram estabelecidas categorias de análise a posteriori.

Sendo assim, por meio das características deste estudo, optou-se por utilizar a pesquisa com abordagem qualitativa, que na concepção de Bogdan e Biklen (1994), esta abordagem de pesquisa possui como características: o ambiente natural como fonte direta de dados, o pesquisador é o instrumento principal da pesquisa; deve ser predominantemente descritiva; os investigadores devem se interessar mais pelo processo do que simplesmente pelos resultados ou produtos; os investigadores tendem a analisar os seus dados de forma indutiva; o significado é de importância vital na abordagem qualitativa. O tipo de pesquisa deste estudo é considerado de "Revisão de Mapeamento", sendo que esse tipo de revisão "mapeia e categoriza a literatura existente a partir de revisões e/ou pesquisas primárias, identificando lacunas na literatura de pesquisa" (SOUSA et al. 2018, p. 48).

Dessa maneira, acreditamos que a pesquisa de abordagem qualitativa do tipo Revisão de Mapeamento se adequa aos objetivos deste estudo, principalmente pelo fato de caracterizar as pesquisas já realizadas sobre o tema e em que contexto elas foram realizadas entre os anos de 2012 a 2019. Sobre este aspecto, o Pibid por ser um programa relativamente recente, ainda

5
Universidade Federal de Mato Grosso, Cuiaba, Mato Grosso, Brasil. Revista REAMEC - Rede Amazonica de 
há poucos trabalhos sobre o tema. A partir do ano de 2012 foram finalizadas as primeiras pesquisas que tinham como tema o Pibid, cujo foco é a sua contribuição na formação inicial de professores de matemática. Assim sendo, a fim de construirmos o corpus deste estudo, recorremos às pesquisas correlatas localizadas na $\mathrm{BDTD}^{1}$ e na $\mathrm{Capes}^{2}$, sendo que a busca nas duas bases foi realizada em maio de 2021.

A busca foi realizada com a string "PIBID" AND "FORMAÇÃO INICIAL DE PROFESSORES" AND "MATEMÁTICA", resultando assim em cento e quarenta e quatro pesquisas encontradas.

Seguindo com o estudo dos títulos e resumos destas pesquisas, procedemos com a exclusão das pesquisas que se encontravam nas duas bases. Posteriormente, foram excluídas pesquisas que tinham como foco os alunos egressos do Pibid por não ser o foco deste estudo e, por fim, foram excluídas pesquisas que, além da matemática, tratavam também de outras disciplinas ou também eram de forma interdisciplinar.

Isso posto, após este último filtro, restaram trinta e sete trabalhos, sendo vinte e seis dissertações e onze teses. Portando, as pesquisas selecionadas possuem como foco além do Pibid, a formação inicial de professores que ensinam matemática e também formação de professores em cursos de Pedagogia voltada aos anos iniciais do Ensino Fundamental.

Assim sendo, atingimos então, o quantitativo de pesquisas que formam o corpus deste artigo. Cabe ainda assinalar, que não foram incluídos na busca das bases da BDTD e Capes artigos e anais de periódicos por entendermos que a quantidade de dissertações e teses encontrados foram suficientes para a realização de uma Revisão de Mapeamento.

Apresentamos a seguir, conforme quadro 1, as pesquisas selecionadas sobre o Pibid que envolvem a formação inicial de professores de matemática. A fim de organizar essas pesquisas, codificamos as dissertações com a letra $\mathrm{D}$ e as teses com a letra $\mathrm{T}$, ordenadas pela ordem cronológica da data de defesa.

\begin{tabular}{|l|l|c|c|c|}
\hline Cód. & \multicolumn{1}{|c|}{ Título } & \multicolumn{1}{|c|}{ Autor(a) } & Ano & Região \\
\hline D01 & $\begin{array}{l}\text { Pibid I/UFPRL: Oficinas pedagógicas que contribuíram para a } \\
\text { autorregulação da aprendizagem e formação docente das bolsistas } \\
\text { de matemática }\end{array}$ & Amanda Pranke & 2012 & Sul \\
\hline D02 & $\begin{array}{l}\text { PIBID: um estudo sobre suas contribuições para o processo } \\
\text { formativo de alunos de Licenciatura em Matemática da PUC-SP }\end{array}$ & $\begin{array}{l}\text { Douglas da Silva } \\
\text { Tinti }\end{array}$ & 2012 & Sudeste \\
\hline
\end{tabular}

\footnotetext{
${ }^{1}$ A BDTD, que integra os sistemas de informação de teses e dissertações existentes nas instituições de ensino e pesquisa do Brasil. Disponível em: https://bdtd.ibict.br/vufind/.

${ }^{2}$ O Catálogo de Teses e Dissertações da Capes disponibiliza resumos de teses e dissertações apresentadas nos programas de pós-graduação do país. Disponível em: https://catalogodeteses.capes.gov.br/. 


\begin{tabular}{|c|c|c|c|c|}
\hline D03 & $\begin{array}{l}\text { Investigando as práticas de ensinar e aprender matemática nos } \\
\text { anos iniciais do ensino fundamental em um grupo do PIBID }\end{array}$ & $\begin{array}{l}\text { Eduardo Manuel } \\
\text { Bartalini } \\
\text { Gallego }\end{array}$ & 2012 & Sudeste \\
\hline D04 & $\begin{array}{l}\text { Programa Institucional de Bolsa de Iniciação à Docência: Ensinar } \\
\text { e Aprender Matemática }\end{array}$ & $\begin{array}{l}\text { Robson Teixeira } \\
\text { Porto }\end{array}$ & 2012 & Sul \\
\hline D05 & $\begin{array}{l}\text { Percepções de licenciandos sobre as contribuições do PIBID- } \\
\text { Matemática }\end{array}$ & $\begin{array}{l}\text { Suzicássia Silva } \\
\text { Ribeiro }\end{array}$ & 2013 & Sudeste \\
\hline D06 & $\begin{array}{l}\text { Formação de professores de Matemática: dimensões presentes na } \\
\text { relação PIBID e comunidade de prática }\end{array}$ & $\begin{array}{l}\text { Vanessa } \\
\text { Cerignoni } \\
\text { Benites }\end{array}$ & 2013 & Sudeste \\
\hline D07 & $\begin{array}{l}\text { O Pibid na Formação Inicial do Licenciando em Matemática: } \\
\text { Construção de Saberes da Experiência Docente }\end{array}$ & $\begin{array}{l}\text { Anna Christina } \\
\text { Alcoforado } \\
\text { Corrêa }\end{array}$ & 2013 & Sudeste \\
\hline D08 & $\begin{array}{l}\text { Formação de professores que ensinam Matemática nos anos } \\
\text { iniciais: contribuições do Programa Institucional de Bolsas de } \\
\text { Iniciação à Docência (PIBID) na UFSCar }\end{array}$ & $\begin{array}{l}\text { Roger Eduardo } \\
\text { Silva Santos }\end{array}$ & 2013 & Sudeste \\
\hline D09 & $\begin{array}{l}\text { O Programa Institucional de Bolsa de Iniciação à Docência - } \\
\text { PIBID na Formação Inicial de Professores de Matemática }\end{array}$ & $\begin{array}{l}\text { Eliton Meireles } \\
\text { de Moura }\end{array}$ & 2013 & Sudeste \\
\hline D10 & 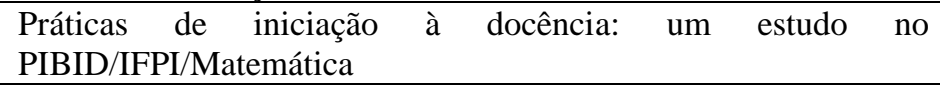 & $\begin{array}{l}\text { Rayssa Martins } \\
\text { de Sousa Neves }\end{array}$ & 2014 & Sul \\
\hline D11 & $\begin{array}{l}\text { Um estudo sobre as contribuições do PIBID-FURB para a } \\
\text { formação inicial de professores de Matemática }\end{array}$ & $\begin{array}{l}\text { Andrea Cristina } \\
\text { Vieira }\end{array}$ & 2014 & $\mathrm{ul}$ \\
\hline D12 & $\begin{array}{l}\text { O PIBID no contexto das políticas de formação de professores de } \\
\text { Biologia e Matemática na Universidade Estadual de Goiás }\end{array}$ & $\begin{array}{ll}\text { Melca } & \text { Moura } \\
\text { Brasil } & \\
\end{array}$ & 2014 & $\begin{array}{l}\text { Centro- } \\
\text { Oeste }\end{array}$ \\
\hline D13 & $\begin{array}{l}\text { Experiências e Narrativas: Um Olhar para a Formação de } \\
\text { Professores de Matemática a Partir do Pibid }\end{array}$ & $\begin{array}{l}\text { Cristina } \\
\text { Schaefer }\end{array}$ & 2015 & Sul \\
\hline D14 & $\begin{array}{l}\text { Impactos do Programa Institucional de Bolsa de Iniciação à } \\
\text { Docência (PIBID) na formação inicial de professores de } \\
\text { Matemática }\end{array}$ & $\begin{array}{l}\text { Danielle } \\
\text { Chistiane dos } \\
\text { Santos Canteiro }\end{array}$ & 2015 & Sudeste \\
\hline D15 & $\begin{array}{l}\text { A Modelagem Matemática na Licenciatura: Uma Experiência no } \\
\text { Pibid }\end{array}$ & $\begin{array}{l}\text { Camila Peixoto } \\
\text { Fagundes } \\
\text { Ramos Duncan }\end{array}$ & 2015 & Sudeste \\
\hline D16 & $\begin{array}{l}\text { Docência: Um olhar para as Práticas Formativas } \\
\text { contexto do PIBID - Matemática/UFLA }\end{array}$ & $\begin{array}{l}\text { Stefânia } \\
\text { Efigênia Izá }\end{array}$ & 2015 & Sudeste \\
\hline D17 & $\begin{array}{l}\text { Contribuições Formativas do Pibid/Matemática: Identidade e } \\
\text { Saberes Docentes }\end{array}$ & $\begin{array}{l}\text { Evaneila Lima } \\
\text { França }\end{array}$ & 2016 & Nordeste \\
\hline D18 & $\begin{array}{l}\text { Programa Institucional de Bolsas de Iniciação à Docência - Pibid } \\
\text { - e a Formação Inicial de Professores }\end{array}$ & $\begin{array}{l}\text { Marcelina } \\
\text { Ferreira Vicente }\end{array}$ & 2016 & Sudeste \\
\hline D19 & $\begin{array}{l}\text { Integração Universidade - Escola: Contribuições do Programa } \\
\text { Institucional de Bolsa de Iniciação à Docência da UFF para a } \\
\text { formação de professores de Matemática }\end{array}$ & $\begin{array}{l}\text { Márcia Milena } \\
\text { da Costa Silva }\end{array}$ & 2016 & Sudeste \\
\hline D20 & $\begin{array}{l}\text { Entre a singularidade e a complexidade da construção de saberes } \\
\text { docentes na formação inicial de professores de matemática no } \\
\text { contexto do Pibid }\end{array}$ & $\begin{array}{l}\text { Iury Sparctton } \\
\text { Melchior de } \\
\text { Abreu }\end{array}$ & 2016 & $\begin{array}{l}\text { Centro- } \\
\text { Oeste }\end{array}$ \\
\hline D21 & $\begin{array}{l}\text { O PIBID de Matemática como espaço de formação inicial e } \\
\text { continuada da UFRN/NATAL }\end{array}$ & $\begin{array}{l}\text { Klêffiton Soares } \\
\text { da Cruz }\end{array}$ & 2017 & Nordeste \\
\hline D22 & $\begin{array}{l}\text { A construção da prática pedagógica dos licenciandos em } \\
\text { Matemática no contexto do Pibid-Uesb de Vitória da Conquista - } \\
\text { Bahia }\end{array}$ & $\begin{array}{ll}\text { Mirian } & \text { Carneiro } \\
\text { de } & \text { Azevedo } \\
\text { Meira } & \\
\end{array}$ & 2017 & Nordeste \\
\hline D23 & $\begin{array}{l}\text { Narrativas (auto)biográficas no PIBID: espaços de } \\
\text { problematização na/para a formação de professores de matemática }\end{array}$ & $\begin{array}{l}\text { Maycon } \\
\text { Douglas Ferreira }\end{array}$ & 2017 & $\begin{array}{l}\text { Centro- } \\
\text { Oeste }\end{array}$ \\
\hline D24 & $\begin{array}{l}\text { Escritas de Licenciados em Matemática, quanto à docência, no } \\
\text { contexto do PIBID }\end{array}$ & Thaís Cosmo & 2017 & Sudeste \\
\hline D25 & $\begin{array}{l}\text { A Importância do PIBID no processo de formação de professores } \\
\text { durante o desenvolvimento do subprojeto de matemática em uma } \\
\text { escola da rede pública do estado de Minas Gerais }\end{array}$ & $\begin{array}{l}\text { Simone Nunes } \\
\text { Vieira Garcia }\end{array}$ & 2018 & Sudeste \\
\hline
\end{tabular}




\begin{tabular}{|c|c|c|c|c|}
\hline D26 & $\begin{array}{l}\text { Singularidades e Subjetividades de um grupo do Pibid na área de } \\
\text { Matemática: Contribuições para o processo de formação de } \\
\text { identidade professoral }\end{array}$ & $\begin{array}{l}\text { Eressiely Batista } \\
\text { Oliveira } \\
\text { Conceição }\end{array}$ & 2019 & Nordeste \\
\hline T01 & $\begin{array}{l}\text { O Pibid e as relações de saber na formação inicial de professores } \\
\text { de Matemática }\end{array}$ & Vanessa Largo & 2013 & Sudeste \\
\hline T02 & $\begin{array}{l}\text { Formação do Professor de Matemática em interface com o PIBID- } \\
\text { Programa Institucional de Bolsa de Iniciação à Docência: } \\
\text { Representações de Licenciandos e Supervisores }\end{array}$ & Silvana Pucetti & 2016 & Sudeste \\
\hline T03 & $\begin{array}{l}\text { Um Estudo da Inserção de Estudantes da Licenciatura em } \\
\text { Matemática no Contexto da Escola Pública: Contribuições do } \\
\text { Pibid }\end{array}$ & $\begin{array}{l}\text { Marcos Pavani } \\
\text { de Carvalho }\end{array}$ & 2016 & Sudeste \\
\hline T04 & $\begin{array}{l}\text { O Pibid e as Relações com o Saber, Aprendizagem da Docência e } \\
\text { Pesquisa: Caracterização de uma Intervenção na Formação Inicial } \\
\text { de Professores de Matemática }\end{array}$ & $\begin{array}{l}\text { Diego Fogaça } \\
\text { Carvalho }\end{array}$ & 2016 & Sul \\
\hline T05 & $\begin{array}{l}\text { Representação social sobre o ensino de Matemática de } \\
\text { licenciandos vinculados ao Pibid: dinâmica de formação }\end{array}$ & $\begin{array}{lr}\text { Silvia } & \text { Regina } \\
\text { Pereira } & \text { de } \\
\text { Mendonça } & \\
\end{array}$ & 2016 & Nordeste \\
\hline T06 & $\begin{array}{l}\text { Potencialidades do PIBID como espaço formativo para } \\
\text { professores de Matemática no Brasil }\end{array}$ & $\begin{array}{ll}\text { Márcio } & \text { Urel } \\
\text { Rodrigues } & \\
\end{array}$ & 2016 & Sudeste \\
\hline T07 & $\begin{array}{l}\text { Características docentes e ações formativas necessárias ao } \\
\text { desenvolvimento profissional na iniciação à docência em } \\
\text { Matemática no âmbito do Pibid }\end{array}$ & $\begin{array}{l}\text { Cristiane } \\
\text { Antonia } \\
\text { Hauschild }\end{array}$ & 2016 & Sul \\
\hline T08 & $\begin{array}{l}\text { Aprender com e sobre a linguagem escrita no Pibid Matemática: } \\
\text { sentidos construídos pelos professores de Matemática em } \\
\text { formação acadêmico-profissional }\end{array}$ & $\begin{array}{l}\text { Liliane Silva de } \\
\text { Antiqueira }\end{array}$ & 2018 & Sul \\
\hline T09 & $\begin{array}{l}\text { PIBID: Significados na formação inicial de professores de } \\
\text { matemática }\end{array}$ & $\begin{array}{l}\text { Maria Aparecida } \\
\text { Silva de Souza }\end{array}$ & 2018 & Sudeste \\
\hline T10 & $\begin{array}{l}\text { Desenvolvimento Profissional Docente e modos de interação no } \\
\text { Planejamento das Atividades do Pibid/Matemática }\end{array}$ & $\begin{array}{l}\text { Francisco José } \\
\text { de Lima }\end{array}$ & 2018 & Sudeste \\
\hline T11 & $\begin{array}{l}\text { Conhecimentos Profissionais Mobilizados/Desenvolvidos por } \\
\text { participantes do Pibid em Práticas de Ensino Exploratório de } \\
\text { Matemática }\end{array}$ & $\begin{array}{l}\text { Alessandra } \\
\text { Senes Marins }\end{array}$ & 2019 & Sul \\
\hline
\end{tabular}

Quadro 1 - Produções que foram selecionadas para este estudo ${ }^{3}$

Fonte: Elaborado pelo autor

\section{PANORAMA SOBRE PESQUISAS BRASILEIRAS QUE ENVOLVEM O PIBID E A FORMAÇÃO INICIAL DE PROFESSORES DE MATEMÁTICA}

Diante deste panorama, uma das primeiras constatações que verificamos no levantamento foi a concentração de produções em programas de Pós-Graduação stricto sensu das regiões Sudeste e Sul, seguidas pelas regiões Nordeste e Centro-Oeste conforme mostrado no gráfico 1. Proporcionalmente falando, na região Norte do país, há menos programas de pósgraduação que nas demais regiões do país. Isso, de certa forma, ajuda-nos a compreender que neste levantamento, não encontramos pesquisas sobre o Pibid e a formação inicial de professores de matemática defendidas em programas de Pós-Graduação sediados na região norte do país cujo foco seja o Pibid em uma das universidades desta mesma região. De toda 
forma, não deixa de ser uma lacuna em se tratado da região Norte do país, e que pesquisas desse tipo devem ser incentivadas pelos programas situados nesta mesma região.

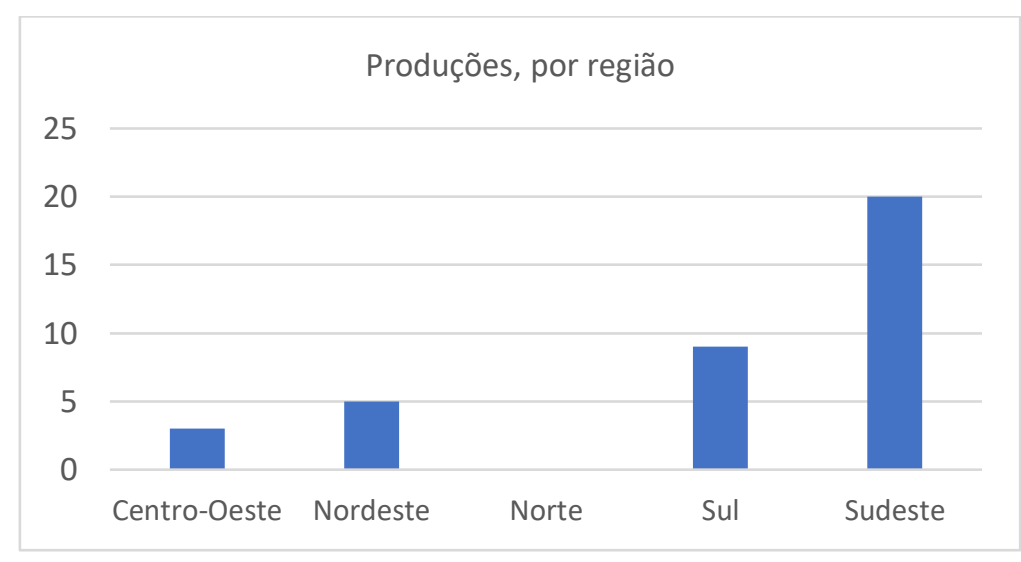

Gráfico 1 - Produções selecionadas distribuídas por região Fonte: Elaborado pelo autor

Nesse cenário, outro dado importante é observado nas produções por ano, pois a maior parte das pesquisas foram realizadas no ano de 2016, conforme gráfico 2, e que a partir do referido ano houve uma redução das produções. Cabe ressaltar que o programa teve seu primeiro ciclo (2007 a 2017) encerrado no início de 2018, e que, a partir do referido ano, o Pibid passou por reformulações constantes no edital $n^{\circ} 7 / 2018$, cujo público-alvo que antes era voltado aos estudantes de licenciatura em qualquer período, passa a ser voltado para os estudantes de licenciatura da primeira metade dos cursos, ou seja, alunos licenciandos que ainda não tenham concluído mais de 60\% da carga horária regimental do curso (CAPES, 2018).

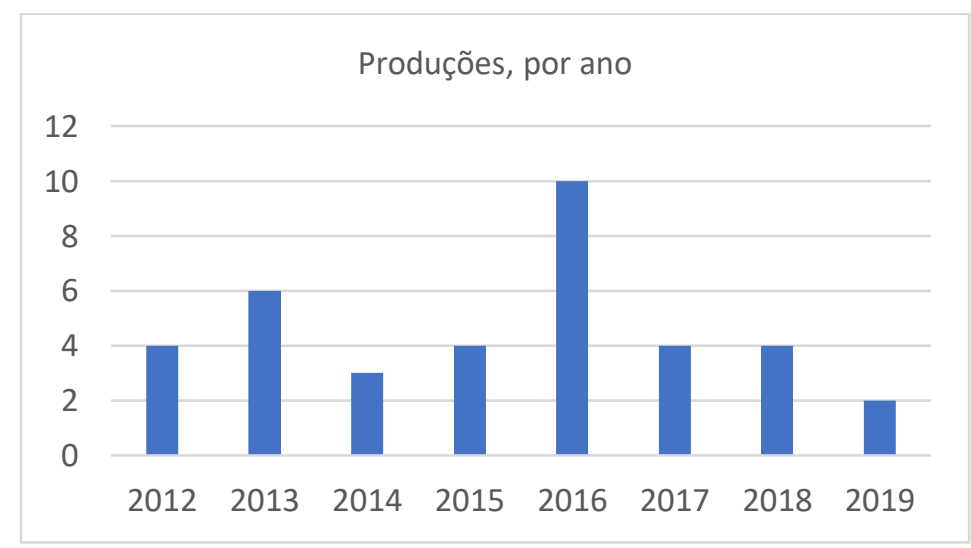

Gráfico 2 - Produções selecionadas distribuídas por ano Fonte: Elaborado pelo autor

A fim de verificarmos outros levantamentos bibliográficos que se aproximam deste estudo e, diante das pesquisas selecionadas, constatamos que os seguintes autores realizaram 
um levantamento às suas épocas: Tinti (2012), Moura (2013), Vieira (2014), Abreu (2016), Rodrigues (2016), Carvalho (2016), Vicente (2016), Ferreira (2017), Lima (2018), Marins (2019) e Conceição (2019). Dentre estes, destacamos a tese de Marins (2019). A autora realiza um levantamento bibliográfico de teses e dissertações defendidas entre os anos de 2010 a 2017 que possuem o Pibid e a formação do professor que ensina matemática como objeto de estudo. No total, a autora abrange trinta e cinco pesquisas. Cabe assinalar, que estas pesquisas compõem algumas das dissertações e teses levantadas pelo presente estudo.

Um outro importante estudo coordenado pelo Grupo de Estudos e Pesquisas sobre Formação de Professores de Matemática (GEPFPM), organizado por Fiorentini, Passos e Lima (2016), teve como objetivo principal o de mapear, descrever e sistematizar as pesquisas brasileiras que têm como foco de estudo o Professor que Ensina Matemática (PEM), produzidas no período de 2001 a 2012, em programas de Pós-graduação stricto sensu das áreas de Educação e Ensino da CAPES. O trabalho foi realizado por grupos de professores distribuídos por todas as regiões do país. Um dos contextos do estudo se trata da "formação inicial/continuada (pesquisas que envolvem futuros professores e professores em exercício, como aqueles que focalizam o PIBID” (FIORENTINI; PASSOS; LIMA, 2016, p. 14). Esta abrangente pesquisa também obteve como parte do seu corpus pesquisas brasileiras que investigaram o Pibid e, desta forma, esta pesquisa teve propósitos que se aproximam deste artigo. A seguir, mostramos o quadro 2 com os tipos de participantes investigados nas pesquisas selecionadas.

\begin{tabular}{|l|l|}
\hline \multicolumn{1}{|c|}{ Sujeitos investigados } & \multicolumn{1}{c|}{ Códigos das pesquisas } \\
\hline I. Licenciandos & D01, T01, D02, D04, D05, T05, D06, D07, T08, D09, \\
& D11, D13, D14, D15, D20, D22, D23, D26 \\
\hline II. Professores supervisores & - \\
\hline III. Coordenadores de área & - \\
\hline IV. Licenciandos e professores supervisores & T02, T04, T11, D25 \\
\hline V. Licenciandos e coordenador de área & D18 \\
\hline VI. Supervisores e coordenador de área & T07, D10 \\
\hline $\begin{array}{l}\text { VII. Licenciandos, Supervisores e Coordenadores de } \\
\text { área }\end{array}$ & T03, D08, T09, T10, D17, D19, D21 \\
\hline $\begin{array}{l}\text { VIII. Licenciandos, Supervisores, Coordenadores de } \\
\text { área e Coordenadores institucionais }\end{array}$ & T06, D12, D24 \\
\hline
\end{tabular}

Quadro 2 - Sujeitos do Pibid abrangidos pelas pesquisas selecionadas de 2012 a 2019 Fonte: Elaboração baseada em Marins (2019, p. 43)

Observa-se no quadro 2 que a maioria das pesquisas abrangem os sujeitos participantes do Pibid, tomando com mais evidência os licenciandos com foco na formação de professores de matemática. Cabe aqui assinalar, que a pesquisas D03 não consta no presente quadro por ter como foco estudantes do curso de Pedagogia. Nesta perspectiva, compactuamos com Lima 
(2018), cujo levantamento bibliográfico de seu estudo também evidenciou que a maior parte das pesquisas tem como foco principal o bolsista de iniciação à docência, juntamente com a sua formação inicial para o exercício da docência.

No que se refere aos procedimentos metodológicos das pesquisas selecionadas, elaboramos um quadro síntese, conforme quadro 3, respectivamente tratando do: tipo de abordagem da pesquisa, tipo de pesquisa e método de análise dos dados. Cabe ressaltar que algumas pesquisas não especificaram alguns desses itens, ou esses não estavam claros, ficando de fora deste levantamento.

\begin{tabular}{|l|l|}
\hline \multicolumn{1}{|c|}{ Quanto à abordagem } & \multicolumn{1}{c|}{ Códigos das pesquisas } \\
\hline Qualitativa & Todas, exceto D20 e T07 \\
\hline Qualiquantitativa & D20, T07 \\
\hline Quanto ao tipo de pesquisa & \\
\hline Estudo de Caso & D01, T02, T07, T10, D15, D16, D17, D18, D20, D22 \\
\hline Analítica interpretativa & D08 \\
\hline Comunidades de Prática & D06, T06 \\
\hline Pesquisa-ação & D13 \\
\hline Grupos Focais & T05, D26 \\
\hline Etnográfica & D09 \\
\hline Quanto à análise dos dados & \\
\hline Análise de Conteúdo & D01, T02, D03, T03, D05, T05, D06, T06, T10, D11, D12, D15, D16, \\
\hline Análise Textual Discursiva (ATD) & T01, D04, T04, T07, T08 \\
\hline Triangulação de dados & D20 \\
\hline Análise do Discurso & D22 \\
\hline Análise de Dados Multidimensionais & T09 \\
\hline
\end{tabular}

Quadro 3 - Procedimentos metodológicos das pesquisas

Fonte: Elaborado pelo autor

Como exposto, observa-se a predominância de pesquisas cuja abordagem é qualitativa, trinta e cinco pesquisas. Outro dado importante se refere ao tipo de pesquisa mais utilizada pelos pesquisadores, sendo o tipo Estudo de Caso, dez pesquisas. Dentre estas as pesquisas que envolviam Estudo de Caso, sete utilizaram a Análise de Conteúdo como método de análise de dados. A saber: D01, T02, T10, D15, D16, D17, D18. Portanto, o quadro 3 nos mostra a predominância de pesquisas qualitativas, do tipo Estudo de Caso que utilizam a Análise de Conteúdo como forma de análise dos dados.

Quanto aos instrumentos de coleta de dados utilizados pelos autores das pesquisas levantadas, observamos que a maioria dessas pesquisas utilizaram variados instrumentos para a coleta, tais como: questionários, entrevistas estruturadas e semiestruturadas, registros escritos, 
diários de campo, análise documental dos relatórios dos subprojetos parciais e finais produzidos pelos bolsistas de iniciação à docência, documentos institucionais do Pibid, gravações em áudio e vídeo, observação participante, acompanhamento das oficinas, encontros presenciais e virtuais, além de narrativas (auto)biográficas.

$\mathrm{Na}$ busca da compreensão das potencialidades do Pibid na formação inicial de professores de matemática, a leitura dos resumos das pesquisas selecionadas e os contextos de análises de cada uma dessas pesquisa nos conduziram à identificação de oito eixos temáticos, conforme quadro 4.

\begin{tabular}{|l|}
\multicolumn{1}{|c|}{ Eixos temáticos } \\
\hline I. Desenvolvimento e conhecimento profissional \\
\hline II. Construção da identidade, saberes e percepções docentes na formação inicial e continuada de professores \\
\hline III. Contribuições do Pibid para a formação de professores de matemática \\
\hline IV. Narrativas e escritas sobre o contexto do Pibid \\
\hline V. O Pibid como política de formação do professor de matemática \\
\hline VI. O Pibid como prática de ensinar e aprender matemática \\
\hline VII. O Pibid como processo de ensino-aprendizagem \\
\hline VIII. Significados, potencialidades e dimensões do Pibid como espaço formativo \\
\hline
\end{tabular}

Quadro 4 - Eixos temáticos

Fonte: Elaborado pelo autor

A seguir, apresentamos a análise dos oito eixos temáticos que possibilitaram elencar elementos que contribuem na formação do inicial do professor de matemática que participa do programa.

\subsection{Desenvolvimento e conhecimento profissional}

Antiqueira (2018) buscou compreender os sentidos construídos pelos professores de matemática em formação acadêmico-profissional, em relação ao aprender com e sobre a linguagem escrita praticada no espaço formativo do Pibid. A autora constatou que a escrita se constituiu um artefato interativo que propiciou a socialização de todos os envolvidos no programa, além disso, foi observado pela autora que a relação entre os integrantes e a prática da linguagem escrita potencializou um espaço de encontro e de escuta.

Voltado também para a contribuição do Pibid na atuação profissional do futuro professor de matemática, Hauschild (2016) se propôs em caracterizar a docência para elaborar e legitimar ações formativas, visando contribuir para a qualificação da iniciação à docência em matemática. 
Nesta mesma via, Lima (2018) e Marins (2019) investigaram os conhecimentos profissionais que são mobilizados/desenvolvidos por participantes do Pibid quando inseridos em um processo formativo.

Já Lima (2018) mostra, em forma de revisão bibliográfica, que o programa tem uma avalição positiva no âmbito da formação professores, e que o programa é reconhecidamente capaz de propiciar a aprendizagem da docência. Contudo, o autor alertava sobre a possibilidade de descontinuidade do programa já em 2018. Descontinuidade essa, que iria sinalizar para a ruptura de um conjunto de ações que poderiam fortalecer a iniciação e a profissão docente no contexto educacional brasileiro.

\subsection{Construção da identidade, saberes e percepções docentes na formação inicial e continuada de professores}

Os trabalhos de Corrêa (2013), Largo (2013), Abreu (2016), Fogaça Carvalho (2016), França (2016) e Conceição (2019) versaram sobre os saberes docentes, a interação e construção desses saberes evidenciados na formação de professores de matemática, oportunizados no contexto do Pibid. Os resultados desses estudos apontaram para contribuições significativas aos seus participantes.

França (2016, p. 10) identificou os saberes mobilizados pelos bolsistas em seus diferentes perfis identitários além de inferir que "quanto maior a diversidade de experiências proporcionadas pelo Pibid, mais oportunidades para que perfis diferentes se encontrem frente à docência e se desenvolvam a partir de suas necessidades". Abreu (2016) analisou as influências do Pibid na construção de saberes docentes, constatando que a relação estabelecida entre a teoria do Ensino Superior e a atuação profissional na Educação Básica contribui tanto para a formação inicial dos bolsistas, assim como para a formação continuada dos professores supervisores.

Corrêa (2013) buscou também uma análise entre as articulações de saberes específicos de matemática e pedagógicos com saberes experienciais da docência, explicitados por licenciandos inseridos no Pibid, em suas vivências do contexto escolar na educação básica.

Aliada a isso, Largo (2013), Fogaça Carvalho (2016) e Conceição (2019) buscaram entender o sentido que os bolsistas de iniciação à docência atribuem na sua relação com o saber, com o ensinar e o aprender, para a construção da identidade professoral, nesse processo de formação. Para Conceição (2019) as relações dos bolsistas com o saber durante o espaço de 
formação do Pibid deram significados aos bolsistas, dentre elas: a própria relação social com o saber (matemático), a relação com o outro e consigo mesmo e pelo desejo de aprenderem a ser professores de Matemática. Os resultados da pesquisa de Largo (2013) identificaram que o espaço de formação do PIDIB propicia momento para mobilizar e articular o seu saber-fazer, constituindo também uma formação continuada dos professores. Do mesmo modo, Fogaça Carvalho (2016) buscou compreender o reflexo que o Pibid proporciona nas relações dos bolsistas com o saber, o aprender e o ensinar matemática.

Além dos saberes docentes, as pesquisas de Moura (2013), Canteiro (2015) e Cruz (2017) buscaram percepções dos participantes sobre a docência e a sua formação, a partir das atividades desenvolvidas no âmbito do Pibid. Para Moura (2013, p. 179), “o espaço de formação propiciado no cotidiano escolar serviu aos bolsistas como quebra de paradigmas". Nesta mesma via, Canteiro (2015) e Cruz (2017) também evidenciaram que a participação no Pibid proporciona aos bolsistas de Matemática aprendizados relevantes à atividade docente, por meio da participação e vivências no contexto escolar, construção e aplicação de procedimentos didáticos, a partir de articulações entre teoria e prática, bem como da problematização de questões relacionadas ao ensino e à aprendizagem. Na percepção de Cruz (2017), os licenciandos vivenciam situações no contexto escolar mediante a construção e aplicação de procedimentos didáticos, a partir de articulações entre teoria e prática, experiências metodológicas e tecnológicas.

Por fim, Vieira (2014) e Vicente (2016) buscaram contextos em que o Pibid contribui para a construção da identidade profissional a partir da formação inicial de professores. Os resultados da pesquisa de Vicente (2016, p. 9) apontaram a "importância de propor ainda no processo de formação inicial de professores, situações em que possibilitem a aproximação dos acadêmicos com o contexto escolar [...]."

Aliado à Vicente (2016), Vieira (2014) identificou algumas contribuições que o Pibid possibilitou aos participantes. Entretanto, na visão da autora, o programa ainda não consegue resolver as defasagens da formação inicial dos professores de matemática, mas que o Pibid se apresenta como um importante aliado dos bolsistas na busca de sua identidade profissional. 


\subsection{Contribuições do Pibid para a formação de professores de matemática}

Santos (2013) buscou identificar e analisar as contribuições do processo de formação docente, em especial em relação à matemática, revelados em narrativas orais e nas produções escritas dos bolsistas.

Nessa mesma via, assim como Santos (2013), Silva (2016) também buscou analisar o Pibid como um processo de formação docente. O autor pôde verificar as contribuições resultantes da parceria entre universidade e escola pública para a formação dos licenciandos. Os resultados de seu estudo indicam que "houve aprendizado significativo dos licenciandos com as atividades desenvolvidas na escola, com os trabalhos apresentados em eventos, elaboração dos materiais e incentivo à pesquisa científica (SILVA, 2016, p. 7).

Já Ribeiro (2013) também buscou analisar as percepções de licenciandos do Pibid de matemática sobre as suas contribuições para o processo formativo do futuro professor. Na visão da autora, os bolsistas compreendem razoavelmente os seus objetivos e percebem parcialmente as implicações positivas para o processo formativo.

Pranke (2012), Tinti (2012) e Carvalho (2016) investigaram as contribuições do Pibid no processo de construção da prática docente de futuros professores de matemática. Para Carvalho (2016, p. 9), “embora as ações do Pibid impulsionem a entrada na carreira dos licenciandos, elas não fornecem subsídios para que construam uma prática docente de modo a favorecer a aprendizagem de conceitos e procedimentos matemáticos de todos os alunos". Pranke (2012), com trabalho focado nas oficinas do Pibid, evidenciou que o desenvolvimento dessas oficinas qualificou a formação inicial dos bolsistas de matemática. Tinti (2012) caracterizou o Pibid como um projeto de "Pré-Docência", pois, na sua visão, para ser um projeto de Iniciação à Docência o programa deveria considerar como bolsistas professores em início de carreira e não licenciandos.

\subsection{Narrativas e escritas sobre o contexto do Pibid}

Schaefer (2015), Cosmo (2015) e Ferreira (2017) analisaram o Pibid sobre a perspectiva de escritas e narrativas dos bolsistas de iniciação à docência. Cosmo (2015) pôde inferir que os futuros professores apresentam em suas escritas uma ampla compreensão sobre o trabalho docente quando inseridos no Pibid. Já Schaefer (2015) passou a considerar as narrativas dos bolsistas e suas possíveis concepções acerca de experiência e aprendizagem matemática. As 
reflexões produzidas durante a sua pesquisa permitiram estudar e problematizar desdobramentos e desafios dessa formação inicial de professores agregadas pelas experiências, observando as contribuições apresentadas e que emergiram da potência narrativa dos bolsistas.

\subsection{O Pibid como política de formação do professor de matemática}

Pucetti (2016) investigou o processo de formação inicial de professores de matemática, tendo como referência discussões e análises aprofundadas sobre o percurso acerca dessa formação no Brasil, sobre as políticas públicas de formação de professores de matemática em interface com a crise das licenciaturas e, também, sobre as concepções e ações que embasam o Pibid e suas representações das experiências com esse programa.

Na mesma via de Pucetti (2016), Garcia (2018) realizou um estudo bibliográfico sobre políticas públicas, formação inicial de professores de matemática e documentos relativos ao Pibid. Diante das reflexões realizadas em seu estudo, foi possível inferir que o Pibid oportunizou um espaço de formação no processo de constituição de professores no cotidiano escolar e, ainda, o quanto o programa coloca os bolsistas à frente da rotina que se faz presente nas escolas.

Nesta mesma via, Moura Brasil (2014) também destacou as políticas públicas voltadas para a formação docente de professores de matemática no Brasil. Para a autora, foi observado nas últimas décadas um avanço nas políticas e nas propostas de formação de professores. Como exemplo, temos as bolsas disponibilizadas aos participantes do programa.

\subsection{O Pibid como prática de ensinar e aprender matemática}

Os estudos de Gallego (2012), Porto (2012), Neves (2014) e Mendonça (2016) foram voltados para as atividades de ensino por meio de práticas pedagógicas direcionadas para o contato com os alunos nas escolas, fazendo com que os bolsistas de iniciação à docência tenham vivência com o cotidiano escolar.

Meira (2017) apontou que a aprendizagem da docência ocorre em diversos momentos, sendo que ela é observadora, interativa, retrospectiva e propicia a reflexão e a problematização do ensino de matemática.

Gallego (2012) e Neves (2014) também tomaram como estudo as práticas de formação inicial de bolsistas de iniciação à docência participantes do programa. Os autores buscaram 
identificar as reflexões produzidas pelos professores sobre os processos de aprender a ensinar matemática e como a matemática escolar é ensinada.

Porto (2012) e Mendonça (2016) buscaram o enfoque da atividade docente na visão dos bolsistas de iniciação à docência durante a atuação no programa. Para Porto (2012, p. 77-78), “a proposta de formação inicial e continuada imbricadas, como sustentada no Pibid, é uma oportunidade de problematização das práticas pedagógicas e do significado de conceitos enquanto a atuação e o experienciar do professor estão sendo exercidos”. Mendonça (2016), ao buscar identificar as representações sociais dos bolsistas do Pibid sobre o ensino de matemática e enfatizar os benefícios do contato com os alunos, concluiu que o Pibid acrescenta benefícios para a formação inicial dos professores.

\subsection{O Pibid como processo de ensino-aprendizagem}

Em seu estudo, Duncan (2015) buscou verificar se os licenciandos consideram que a Modelagem Matemática pode auxiliá-los de forma significativa, no processo de ensinoaprendizagem e de que modo a vivência com esta metodologia pode contribuir para a prática docente dos futuros professores.

Como resultado, foi verificado pelos licenciados que a Modelagem pode ser considerada uma metodologia eficaz no ensino/aprendizagem da Matemática, além de proporcionar-lhes grande contribuição para a prática docente enquanto futuros professores de matemática. Izá (2015) e Meira (2017), também buscaram identificar como se dá a aprendizagem da docência e analisou as reflexões produzidas pelos licenciandos sobre a experiência de constituir-se profissionalmente no contexto Pibid.

\subsection{Significados, potencialidades e dimensões do Pibid como espaço formativo}

Benites (2013), Rodrigues (2016) e Souza (2018) buscaram investigar o Pibid de uma forma mais abrangente, buscando mais significados para o programa e o tendo como outro espaço para a formação inicial de professores de matemática.

Desta forma, Benites (2013, p. 168) defendeu a "ideia do trabalho colaborativo, entre Universidade-Escola, num movimento de constante transformação, em que os futuros professores possam minimizar parte de suas inseguranças perante o trabalho docente". 
Nesta direção, Souza (2018) também apontou um trabalho colaborativo, mas entre instituições de ensino que participam do programa. Percebendo o Pibid de uma forma mais abrangente, Rodrigues (2016) mostrou as potencialidades do Pibid como "Terceiro Espaço" para a formação de professores de matemática no Brasil.

\section{CONSIDERAÇÕES}

Com o início das defesas das pesquisas brasileiras de mestrado e doutorado sobre o Pibid a partir de 2012, praticamente dez anos de pesquisas, buscamos investigar, nesse período, como o Pibid atua na formação do futuro professor de matemática e, a partir disso foi possível construirmos oito eixos temáticos que possibilitaram elencar elementos que contribuem na formação do futuro professor de matemática que participa do programa.

Cabe, ainda, assinalar quanto aos sujeitos envolvidos nas pesquisas, em sua maioria, são participantes do programa, conforme quadro 2. No entanto, não foi encontrado, neste levantamento, pesquisas que tratavam da percepção do aluno da educação básica sobre o Pibid.

Em linha gerais, a partir do objetivo principal da pesquisa, foi possível inferir a partir do levantamento bibliográfico, que as pesquisas apontam o Pibid como um espaço para a formação inicial dos bolsistas e também para a formação continuada e que o programa permite construir saberes docentes, possibilitando reflexões sobre as práticas formativas desenvolvidas, além de inserir o futuro professor nas práticas de ensinar e aprender. Entretanto, há lacunas apontadas pelos pesquisadores, tais como: baixo número de bolsas disponibilizadas que, dessa forma favorece uma pequena parte dos licenciandos das universidades e a necessidade de uma avaliação externa mais profunda sobre o programa.

Cabe ressaltar que, atualmente, em tempo de pandemia de Covid- $19^{4}$, há necessidade de mais pesquisas que envolvam o Pibid juntamente com o uso das Tecnologias Digitais da Informação e Comunicação (TDIC) correlacionadas à vivência com essas tecnologias por parte dos envolvidos pelo programa. Além do que, o isolamento social imposto pela pandemia fez com que o uso dessas tecnologias se tornasse crucias para a continuidade das atividades do programa mesmo que de forma remota. Outro ponto importante foi a profunda mudança que o ocorreu no programa em 2018, carecendo assim de mais pesquisas sobre o Pibid após este período.

${ }^{4}$ Em 11 de março de 2020, a Organização Mundial de Saúde (OMS) declarou o novo coronavírus (covid-19) como
pandemia. 


\section{REFERENCIAS}

BOGDAN, Robert C.; BIKLEN, Sari Knopp. Características da investigação qualitativa. In: Investigação qualitativa em Educação: uma introdução à teoria e aos métodos, Editora Porto, 1994.

BRASIL, CAPES. Edital 07/2018, de 01 de março de 2018. PIBID - Chamada Pública para apresentação de propostas. Disponível em:

https://pibid.ufba.br/sites/pibid.ufba.br/files/edital-7-pibid-retificado__0.pdf. Acesso em 16 jun. 2021.

BRASIL, CAPES. Portaria Gab N 259, de 17 de dezembro de 2019. Dispõe sobre o regulamento do Programa de Residência Pedagógica e do Programa Institucional de Bolsa de Iniciação (PIBID) Disponível em: SEI/CAPES - 1118576 - Portaria GAB (www.gov.br). Acesso em: 22 dez. 2021.

BRASIL, CAPES. Portaria Normativa $\mathbf{n}^{0}$ 38, de 12 de dezembro de 2007. Dispõe sobre o Programa de Bolsa Institucional de Iniciação à Docência - PIBID. Disponível em: http://portal.mec.gov.br/arquivos/pdf/portaria_pibid.pdf. Acesso em: 19 mai. 2021.

BRASIL, CAPES. Portaria Normativa n 122, de 16 de setembro de 2009. Dispõe sobre o PIBID - Programa Institucional de Bolsa de Iniciação à Docência, no âmbito da CAPES. Disponível em: https://pibid.unespar.edu.br/noticias/portaria-normativa-capes-no-122-de-16de-setembro-de-2009.pdf. Acesso em 27 mai. 2021.

BRASIL, CAPES. Diretoria de Educação Básica Presencial (DEB)/CAPES. Relatório de Gestão 2009 - 2014. Disponível em: https://docs.uft.edu.br/page/site/puft/documentdetails?nodeRef=workspace://SpacesStore/1b2f5787-1a41-4fd8-bac2-740adfef27ad. Acesso em 28 mai. 2021.

FIORENTINI, Dário.; PASSOS, Cármen Lúcia Brancaglion.; LIMA, Rosana Catarina Rodrigues de. Mapeamento da pesquisa acadêmica brasileira sobre o professor que ensina matemática: período 2001 - 2012. Campinas: FE/Unicamp, 2016.

GATTI, Bernardete Angelina.; ANDRÉ, Marli Elisa Dalmazo Afonso.; GIMENES, Nelson Antonio Simão.; FERRAGUT, Laurizete. Um estudo avaliativo do Programa Institucional de Bolsas de Iniciação à Docência (Pibid). 41. ed. São Paulo: FCC/SEP, 2014. Disponível em: https://www2.unesp.br/portal\#!/prograd/pibid18080/publicacoes/avaliacao-pibid-ffc/. Acesso em 28 mai. 2021.

SOUSA, Luís Manuel Mota; FIRMINO, Cristiana Furtado; MARQUES-VIEIRA, Cristina Maria Alves; SEVERINO, Sandy Silva Pedro Severino; PESTANA, Helena Castelão Figueira Carlos. Revisões da Literatura Científica: Tipos, Métodos e Aplicações em Enfermagem. Revista Portuguesa de Enfermagem de Reabilitação, Lisboa, v. 1, n.1, p. 46-55, jun. 2018.

Referências das obras revisadas 
ABREU, Iury Sparctton Melchior de. Entre a singularidade e a complexidade da construção de saberes docentes na formação inicial de professores de matemática no contexto do pibid. 2016. 160 f. Dissertação (Mestrado) - Universidade Federal de Goiás, Programa de Pós-Graduação em Educação em Ciências e Matemática, Goiânia, 2016.

Disponível em: http://repositorio.bc.ufg.br/tede/handle/tede/6533. Acesso em 16 jun. 2021.

ANTIQUEIRA, Liliane Silva de. O Aprender com e sobre a linguagem escrita no Pibid Matemática: sentidos construídos pelos professores de Matemática em formação acadêmico-profissional. 2018. 231 f. Tese (Doutorado) - Universidade Federal do Rio Grande, Programa de Pós-Graduação em Educação em Ciências: Química da Vida e Saúde, Rio Grande, 2018. Disponível em: http://repositorio.furg.br/handle/1/8452. Acesso em 16 jun. 2021.

BENITES, Vanessa Cerignoni. Formação de professores de Matemática: dimensões presentes na relação PIBID e comunidade de prática. 2013. 247 f. Dissertação (Mestrado) Universidade Estadual Paulista, Instituto de Geociências e Ciências Exatas, Programa de PósGraduação em Educação Matemática, Rio Claro, 2013. Disponível em: https://repositorio.unesp.br/handle/11449/91031. Acesso em 16 jun. 2021.

BRASIL, Melca Moura. O PIBID no contexto das políticas de formação de professores de Biologia e Matemática na Universidade Estadual de Goiás. 2014. 127 f. Dissertação (Mestrado) - Universidade Federal de Goiás, Programa de Pós-Graduação em Educação em Ciências e Matemática, Goiânia, 2014. Disponível em: http://repositorio.bc.ufg.br/tede/handle/tede/4831. Acesso em 16 jun. 2021.

CANTEIRO, Danielle Chistiane dos Santos. Impactos do Programa Institucional de Bolsa de Iniciação à Docência (PIBID) na formação inicial de professores de Matemática. 2015. 109 f. Dissertação (Mestrado) - Universidade de São Paulo, Faculdade de Educação, Programa de Pós-Graduação em Educação, São Paulo, 2015. Disponível em: https://www.teses.usp.br/teses/disponiveis/48/48134/tde-03082015-151954/pt-br.php. Acesso em 16 jun. 2021.

CARVALHO, Diego Fogaça. O Pibid e as Relações com o Saber, Aprendizagem da Docência e Pesquisa: Caracterização de uma Intervenção na Formação Inicial de Professores de Matemática. 2016. 243 f. Tese (Doutorado) - Universidade Estadual de Londrina, Centro de Ciências e Matemática, Programa de Pós-Graduação em Ensino de Ciências e Educação Matemática, Londrina, 2016. Disponível em: http://www.bibliotecadigital.uel.br/document/?code=vtls000206558. Acesso em 16 jun. 2021.

CARVALHO, Marcos Pavani de. Um Estudo da Inserção de Estudantes da Licenciatura em Matemática no Contexto da Escola Pública: Contribuições do Pibid. 2016. 209 f. Tese (Doutorado) - Universidade Anhanguera de São Paulo, Coordenadoria de Pós-graduação, Programa de Pós-Graduação em Educação Matemática, São Paulo, 2016. Disponível em: http://enfoqueontosemiotico.ugr.es/tesis/Tese_MPavani_Carvalho.pdf. Acesso em: 16 jun. 2021.

CONCEIÇÃO, Eressiely Batista Oliveira. Singularidades e Subjetividades de um grupo do Pibid na área de Matemática: Contribuições para o processo de formação de identidade professoral. 2019. 187 f. Dissertação (Mestrado) - Universidade Federal de Sergipe, Núcleo 
de Pós-Graduação em Ensino de Ciências Naturais e Matemática, São Cristóvão, 2019. Disponível em:

https://ri.ufs.br/bitstream/riufs/11535/2/ERESSIELY_BATISTA_OLIVEIRA_CONCEICAO. pdf. Acesso em 16 jun. 2021.

CORRÊA, Anna Christina Alcoforado. O Pibid na Formação Inicial do Licenciando em Matemática: Construção de Saberes da Experiência Docente. 2013. 92 f. Dissertação (Mestrado) - Instituto Federal do Espírito Santo, Programa de Pós-Graduação em Educação em Ciências e Matemática, Vitória, 2013. Disponível em:

https://repositorio.ifes.edu.br/handle/123456789/229. Acesso em 16 jun. 2021.

COSMO, Thaís. Escritas de Licenciados em Matemática, quanto à docência, no contexto do PIBID. 2015. 185 f. Dissertação (Mestrado) - Universidade Federal de São Carlos, Programa de Pós-Graduação em Educação, São Carlos, 2015. Disponível em: https://repositorio.ufscar.br/handle/ufscar/8463. Acesso em 16 jun. 2021.

CRUZ, Klêffiton Soares da. O PIBID de Matemática como espaço de formação inicial e continuada da UFRN/NATAL. 2017. 343 f. Dissertação (Mestrado) - Universidade Federal do Rio Grande do Norte, Programa de Pós-Graduação em Ensino de ciências Naturais e Matemática, Natal, 2017. Disponível em:

https://repositorio.ufrn.br/handle/123456789/24231. Acesso em 16 jun. 2021.

DUNCAN, Camila Peixoto Fagundes Ramos. A Modelagem Matemática na Licenciatura: Uma Experiência no Pibid a Modelagem Matemática na Licenciatura: Uma experiência no PIBID. 2015. 125 f. Dissertação (Mestrado) - Universidade Estadual do Norte Fluminense Darcy Ribeiro, Centro de Ciências do Homem, Programa de Pós-Graduação em Cognição e Linguagem, Campos dos Goytacazes, 2015. Disponível em:

http://www.pgcl.uenf.br/arquivos/dissertacaocamilapeixotofagundesramosduncan_030920191353.pdf. Acesso em 16 jun. 2021.

FERREIRA, Maycon Douglas. Narrativas (auto)biográficas no PIBID: espaços de problematização na/para a formação de professores de matemática. 2017. 229 f. Dissertação (Mestrado) - Universidade Federal de Mato Grosso do Sul, Programa de Pós-Graduação em Educação Matemática, Campo Grande, 2017. Disponível em:

https://repositorio.ufms.br/handle/123456789/3168. Acesso em 16 jun. 2021.

FRANÇA, Evaneila Lima. Contribuições Formativas do Pibid/Matemática: Identidade e Saberes Docentes. 2016. 128 f. Dissertação (Mestrado) - Universidade Estadual de Santa Cruz, Programa de Pós-Graduação em Educação Matemática, Ilhéus, 2016. Disponível em: https://sucupira.capes.gov.br/sucupira/public/consultas/coleta/trabalhoConclusao/viewTrabalh oConclusao.jsf?popup=true\&id trabalho=3667105. Acesso em 16 jun. 2021.

GALLEGO, Eduardo Manuel Bartalini. Investigando as práticas de ensinar e aprender matemática nos anos iniciais do ensino fundamental em um grupo do PIBID. 2012. $121 \mathrm{f}$. Dissertação (Mestrado) - Universidade São Francisco, Programa de Pós-Graduação Stricto Sensu em Educação, Itatiba, 2012. Disponível em: https://www.usf.edu.br/galeria/getImage/385/424769746349333.pdf. Acesso em 16 jun. 2021. 
GARCIA, Simone Nunes Vieira. A Importância do PIBID no processo de formação de professores durante o desenvolvimento do subprojeto de matemática em uma escola da rede pública do estado de Minas Gerais. 2018. 136 f. Dissertação (Mestrado) Universidade Federal de Uberlândia, Programa de Pós-Graduação em Ensino de Ciências e Matemática, Uberlândia, 2018. Disponível em:

https://sucupira.capes.gov.br/sucupira/public/consultas/coleta/trabalhoConclusao/viewTrabalh oConclusao.jsf?popup=true\&id trabalho=7604491. Acesso em 16 jun. 2021.

HAUSCHILD, Cristiane Antonia. Características docentes e ações formativas necessárias ao desenvolvimento profissional na iniciação à docência em Matemática no âmbito do Pibid. 2016. 164 f. Tese (Doutorado) - Universidade Católica do Rio Grande do Sul, Programa de Pós-Graduação em Educação em Ciências e Matemática, Porto Alegre, 2016. Disponível em: http://tede2.pucrs.br/tede2/handle/tede/7015. Acesso em 16 jun. 2021.

IZÁ, Stefânia Efigênia. Aprendizagem da Docência: Um olhar para as Práticas Formativas desenvolvidas no contexto do PIBID - Matemática/UFLA. 2015. 151 f. Dissertação (Mestrado) - Universidade Federal de São João del-Rei, Departamento de Ciências da Educação, Programa de Pós-graduação em Educação: Processos Socioeducativos e Práticas Escolares, São João del-Rei, 2015. Disponível em: https://www.ufsj.edu.br/portal2repositorio/File/mestradoeducacao/Dissertacao\%20Stefania\%20Efigenia\%20Iza.pdf. Acesso em 16 jun. 2021.

LARGO, Vanessa. O Pibid e as relações de saber na formação inicial de professores de Matemática. 2013. 220 f. Tese (Doutorado) - Universidade Estadual de Londrina, Centro de Ciências Exatas, Programa de Pós-Graduação em Ensino de Ciências e Educação Matemática, Londrina, 2013. Disponível em:

http://www.bibliotecadigital.uel.br/document/?code=vtls000185182. Acesso em 16 jun. 2016.

LIMA, Francisco José de. Desenvolvimento Profissional Docente e modos de interação no Planejamento das Atividades do Pibid/Matemática. 2018. 150 f. Tese (Doutorado) Universidade Metodista de Piracicaba, Faculdade de Ciências Humanas, Programa de PósGraduação em Educação, Piracicaba, 2018. Disponível em:

http://iepapp.unimep.br/biblioteca_digital/visualiza.php?cod=MTgxMg. Acesso em 16 jun. 2021.

MARINS, Alessandra Senes. Conhecimentos Profissionais Mobilizados/Desenvolvidos por participantes do Pibid em Práticas de Ensino Exploratório de Matemática. 2019. 225 f. Tese (Doutorado) - Universidade Estadual de Londrina, Centro de Ciências Exatas, Programa de Pós-Graduação em Ensino de Ciências e Educação Matemática, Londrina, 2019. Disponível em: http://www.bibliotecadigital.uel.br/document/?code=vtls000226171. Acesso em 16 jun. 2021.

MEIRA, Mirian Carneiro de Azevedo. A construção da prática pedagógica dos licenciandos em Matemática no contexto do Pibid-Uesb de Vitória da Conquista - Bahia. 2017. 139 f. Dissertação (Mestrado) - Universidade Estadual do Sudoeste da Bahia, Programa de Pós-Graduação em Educação, Vitória da Conquista, 2017. Disponível em: http://www2.uesb.br/ppg/ppged/wp-content/uploads/2017/05/Disserta\%C3\%A7\%C3\%A3oMirian-Carneiro-de-Azevedo-Meira.pdf. Acesso em 16 jun. 2021. 
MENDONÇA, Silvia Regina Pereira de. Representação social sobre o ensino de Matemática de licenciandos vinculados ao Pibid: dinâmica de formação. 2016. 295 f. Tese (Doutorado) - Universidade Federal do Rio Grande do Norte, Centro de Educação, Programa de Pós-Graduação em Educação, Natal, 2016. Disponível em:

https://repositorio.ufrn.br/jspui/handle/123456789/21950. Acesso em 16 jun. 2021.

MOURA, Eliton Meireles de. O Programa Institucional de Bolsa de Iniciação à Docência - PIBID na Formação Inicial de Professores de Matemática. 2013. 197 f. Dissertação (Mestrado) - Universidade Federal de Uberlândia, Programa de Pós-Graduação em Educação, Uberlândia, 2013. Disponível em:

https://repositorio.ufu.br/bitstream/123456789/13924/1/Eliton\%20Meireles.pdf. Acesso em 16 jun. 2021.

NEVES, Rayssa Martins de Sousa. Práticas de iniciação à docência: um estudo no PIBID/IFPI/Matemática. 2014. 112 f. Dissertação (Mestrado) - Universidade do Vale do Rio dos Sinos, Programa de Pós-Graduação em Educação, São Leopoldo, 2014. Disponível em: http://www.repositorio.jesuita.org.br/handle/UNISINOS/3107. Acesso em 16 jun. 2021.

PORTO, Robson Teixeira. Programa Institucional de Bolsa de Iniciação à Docência: Ensinar e Aprender Matemática. 2012. 96 f. Dissertação (Mestrado) - Universidade Federal do Rio Grande, Programa de Pós-Graduação em Educação em Ciências: Química da Vida e Saúde, Rio Grande, 2012. Disponível em: http://repositorio.furg.br/handle/1/4785. Acesso em 16 jun. 2021.

PRANKE, Amanda. Pibid I/UFPRL: Oficinas pedagógicas que contribuíram para a autorregulação da aprendizagem e formação docente das bolsistas de matemática. 2012. $136 \mathrm{f}$. Dissertação (Mestrado) - Universidade Federal de Pelotas, Programa de Pós-Graduação em Educação, Pelotas, 2012. Disponível em:

http://guaiaca.ufpel.edu.br:8080/handle/123456789/1631. Acesso em 16 jun. 2021.

PUCETTI, Silvana. Formação do Professor de Matemática em interface com o PIBIDPrograma Institucional de Bolsa de Iniciação à Docência: Representações de Licenciandos e Supervisores. 2016. 259 f. Tese (Doutorado) - Universidade Metodista de São Paulo, Escola de Comunicação, Educação e Humanidades, Programa de Pós-Graduação em Educação, São Bernardo do Campo, 2016. Disponível em:

http://tede.metodista.br/jspui/handle/tede/1622. Acesso em: 16 jun. 2021.

RIBEIRO, Suzicássia Silva. Percepções de licenciandos sobre as contribuições do PIBIDMatemática. 2013. 212 f. Dissertação (Mestrado) - Universidade Federal de Lavras, Programa de Pós-Graduação em Educação, Lavras, 2013. Disponível em: http://repositorio.ufla.br/jspui/handle/1/1460. Acesso em 16 jun. 2021.

RODRIGUES, Márcio Urel. Potencialidades do PIBID como espaço formativo para professores de Matemática no Brasil. 2016. 540 f. Tese (Doutorado) - Universidade Estadual Paulista, Instituto de Geociências e Ciências Exatas, Programa de Pós-Graduação em Educação Matemática, Rio Claro, 2016. Disponível em: http://hdl.handle.net/11449/146706. Acesso em 16 jun. 2021. 
SANTOS, Roger Eduardo Silva. Formação de professores que ensinam Matemática nos anos iniciais: contribuições do Programa Institucional de Bolsas de Iniciação à Docência (PIBID) na UFSCar. 2013. 105 f. Dissertação (Mestrado) - Universidade Federal de São Carlos, Programa de Pós-Graduação em Educação do Centro de Educação e Ciências Humanas, São Carlos, 2013. Disponível em: https://repositorio.ufscar.br/handle/ufscar/2743. Acesso em 16 jun. 2021.

SCHAEFER, Cristina. Experiências e Narrativas: Um Olhar para a Formação de Professores de Matemática a Partir do Pibid. 2015. 71 f. Dissertação (Mestrado) Universidade de Santa Cruz do Sul, Programa de Pós-Graduação em Educação, Santa Cruz do Sul, 2015. Disponível em: http://hdl.handle.net/11624/514. Acesso em 16 jun. 2021.

SILVA, Márcia Milena da Costa. Integração Universidade - Escola: Contribuições do Programa Institucional de Bolsa de Iniciação à Docência da UFF para a formação de professores de Matemática. 2016. 176 f. Dissertação (Mestrado) - Universidade Estácio de Sá, Programa de Pós-Graduação em Educação, Rio de Janeiro, 2016. Disponível em: https://sucupira.capes.gov.br/sucupira/public/consultas/coleta/trabalhoConclusao/viewTrabalh oConclusao.jsf?popup=true\&id_trabalho=4131370. Acesso em 16 jun. 2021.

SOUZA, Maria Aparecida Silva de. PIBID: Significados na formação inicial de professores de matemática. 2018. 206 f. Tese (Doutorado) - Pontifícia Universidade Católica de São Paulo, Programa de Estudos Pós-Graduados em Educação Matemática, São Paulo, 2018. Disponível em: https://tede2.pucsp.br/handle/handle/22219. Acesso em 16 jun. 2021.

TINTI, Douglas da Silva. PIBID: um estudo sobre suas contribuições para o processo formativo de alunos de Licenciatura em Matemática da PUC-SP. 2012. 146 f. Dissertação (Mestrado) - Pontifícia Universidade Católica de São Paulo, Programa de Estudos PósGraduados em Educação Matemática, São Paulo, 2012. Disponível em: https://tede2.pucsp.br/handle/handle/10931. Acesso em 16 jun. 2021.

VICENTE, Marcelina. Ferreira. Programa Institucional de Bolsas de Iniciação à Docência - Pibid - e a Formação Inicial de Professores. 2016. 170 f. Dissertação (Mestrado) Universidade Estadual Paulista, Faculdade de Ciências e Tecnologia, Programa de PósGraduação em Educação, Presidente Prudente, 2016. Disponível em:

https://repositorio.unesp.br/bitstream/handle/11449/136468/vicente_mf_me_prud.pdf?sequen $\underline{\mathrm{ce}=3}$. Acesso em 16 jun. 2021.

VIEIRA, Andrea Cristina. Um estudo sobre as contribuições do PIBID-FURB para a formação inicial de professores de Matemática. 2014. 99 f. Dissertação (Mestrado) Universidade Regional de Blumenau, Centro de Ciências Exatas e Naturais, Programa de PósGraduação em Ensino de Ciências Naturais e Matemática, Blumenau, 2014. Disponível em: https://bu.furb.br//docs/DS/2014/358798_1_1.pdf. Acesso em 16 jun. 2021.

\section{APÊNDICE 1}

\section{AGRADECIMENTOS}

Agradecemos à Universidade Federal do Norte do Tocantins (UFNT) e ao Programa de Pós-Graduação em Ensino de Ciências e Matemática (PPGecim) da UFNT. 


\title{
FINANCIAMENTO
}

Não se aplica.

\section{CONTRIBUIÇÕES DE AUTORIA}

Resumo/Abstract/Resumen: Marcos Antonio de Sousa; Deive Barbosa Alves; Ulisses Queiroz Parreira Introdução: Marcos Antonio de Sousa; Deive Barbosa Alves; Ulisses Queiroz Parreira Referencial teórico: Marcos Antonio de Sousa; Deive Barbosa Alves; Ulisses Queiroz Parreira Análise de dados: Marcos Antonio de Sousa; Deive Barbosa Alves; Ulisses Queiroz Parreira Discussão dos resultados: Marcos Antonio de Sousa; Deive Barbosa Alves; Ulisses Queiroz Parreira Conclusão e considerações finais: Marcos Antonio de Sousa; Deive Barbosa Alves; Ulisses Queiroz Parreira Referências: Marcos Antonio de Sousa; Deive Barbosa Alves; Ulisses Queiroz Parreira Revisão do manuscrito: Marcos Antonio de Sousa; Deive Barbosa Alves; Ulisses Queiroz Parreira Aprovação da versão final publicada: Marcos Antonio de Sousa; Deive Barbosa Alves; Ulisses Queiroz Parreira

\section{CONFLITOS DE INTERESSE}

Os autores declararam não haver nenhum conflito de interesse de ordem pessoal, comercial, acadêmico, político e financeiro referente a este manuscrito.

\section{DISPONIBILIDADE DE DADOS DE PESQUISA}

O conjunto de dados que dá suporte aos resultados da pesquisa foi publicado no próprio artigo.

CONSENTIMENTO DE USO DE IMAGEM

Não se aplica.

\author{
APROVAÇÃO DE COMITÊ DE ÉTICA EM PESQUISA \\ Não se aplica.
}

\section{COMO CITAR - ABNT}

SOUSA, Marcos Antonio de. ALVES, Deive Barbosa. PARREIRA, Ulisses Queiroz. Um mapeamento de pesquisas brasileiras sobre o Pibid e a formação inicial de professores de matemática. REAMEC - Rede Amazônica de Educação em Ciências e Matemática. Cuiabá, v. 9, n. 3, e21101, set./dez., 2021. https://doi.org/10.26571/reamec.v9i3.12931.

\section{COMO CITAR - APA}

Sousa, M. A., Alves, D. B., Parreira, U. Q. (2021). Um mapeamento de pesquisas brasileiras sobre o Pibid e a formação inicial de professores de matemática. REAMEC - Rede Amazônica de Educação em Ciências e Matemática, 9 (3), e21101. https://doi.org/10.26571/reamec.v9i3.12931.

\section{LICENÇA DE USO}

Licenciado sob a Licença Creative Commons Attribution-NonCommercial 4.0 International (CC BY-NC 4.0). Esta licença permite compartilhar, copiar, redistribuir o manuscrito em qualquer meio ou formato. Além disso, permite adaptar, remixar, transformar e construir sobre o material, desde que seja atribuído o devido crédito de autoria e publicação inicial neste periódico.

\section{DIREITOS AUTORAIS}

Os direitos autorais são mantidos pelos autores, os quais concedem à Revista REAMEC - Rede Amazônica de Educação em Ciências e Matemática - os direitos exclusivos de primeira publicação. Os autores não serão remunerados pela publicação de trabalhos neste periódico. Os autores têm autorização para assumir contratos adicionais separadamente, para distribuição não exclusiva da versão do trabalho publicada neste periódico (ex.: publicar em repositório institucional, em site pessoal, publicar uma tradução, ou como capítulo de livro), com reconhecimento de autoria e publicação inicial neste periódico. Os editores da Revista têm o direito de proceder a ajustes textuais e de adequação às normas da publicação.

\section{PUBLISHER}

Universidade Federal de Mato Grosso. Programa de Pós-graduação em Educação em Ciências e Matemática (PPGECEM) da Rede Amazônica de Educação em Ciências e Matemática (REAMEC). Publicação no Portal de 
Periódicos UFMT. As ideias expressadas neste artigo são de responsabilidade de seus autores, não representando, necessariamente, a opinião dos editores ou da referida universidade.

\section{EDITOR}

Geslane Figueiredo da Silva Santana

\section{HISTÓRICO}

Submetido: 02 de setembro de 2021.

Aprovado: 08 de dezembro de 2021.

Publicado: 23 de dezembro de 2021. 